\title{
Identification and characterisation of a cytotoxic porin-lipopolysaccharide complex from Campylobacter jejuni
}

\author{
DAVID J. BACON*, WENDY M. JOHNSON† and FRANK G. RODGERS
}

Department of Microbiology, Rudman Hall, University of New Hampshire, Durham, NH 03824-2617, USA and $\uparrow$ Bureau of Microbiology, Laboratory Centre for Disease Control, Tunney's Pasture, Ottawa, Ontario K1A OL2, Canada

\begin{abstract}
A clinical isolate of Campylobacter jejuni, previously found to produce a toxin active in cell culture assays, was used for identification and characterisation of a cytotoxic porinlipopolysaccharide (LPS) complex. This cytotoxic complex was isolated by highperformance liquid chromatography of crude concentrated culture supernate and DEAE-anion exchange chromatography. The complex had a toxic activity of 20.1 tissue culture dose50 (TCD50) $/ \mu \mathrm{g}$ of protein for HEp-2 cells, $7.49 \mathrm{TCD50} / \mu \mathrm{g}$ of protein for HeLa cells and $1.87 \mathrm{TCD50} / \mu \mathrm{g}$ of protein for Chinese hamster ovary cells. Analysis by SDS-PAGE revealed a single protein band of $45 \mathrm{kDa}$ and a high mol. wt carbohydrate moiety. The complex gave a positive result in the Limulus amoebocyte lysate test, indicating that the co-purifying carbohydrate was LPS, and had specificity for the lectins Galanthus nivalis agglutinin, Maackia amurensis agglutinin and Datura stramonium agglutinin. The cytotoxic activity associated with the complex was heatlabile at $70^{\circ} \mathrm{C}$, resistant to inactivation with trypsin and retained activity after treatment with sodium metaperiodate and the glycosidases neuraminidase and $\mathbf{N}$-glycosidase $\mathbf{F}$. Sequencing of the $\mathrm{N}$-terminus of the protein component of the complex revealed $97 \%$ homology with the major outer-membrane porin protein from $C$. jejuni. The cytotoxic activity of the complex was neutralised by a polyclonal, homologous antiserum, which reacted on Western blot with the $45-\mathrm{kDa}$ protein, but not by polyclonal antisera raised against a number of other bacterial toxins.
\end{abstract}

\section{Introduction}

Campylobacter jejuni is a major cause of bacterial gastro-enteritis in developed and developing countries. Active surveys conducted in the USA have estimated the incidence of gastro-enteritis associated with $C$. jejuni to be 1 case per 100 of the population and this corresponds to $c$. 2.5 million cases per year [1]. This estimated rate is twice that reported for salmonellosis and four times that for shigellosis [2]. Although campylobacteriosis can persist for up to 7 days, most cases are self-limiting and only occasional instances require antibiotic and rehydration therapy for effective treatment.

Received 17 Feb. 1998; revised version received 5 June 1998; accepted 22 June 1998.

Corresponding author: Professor F. G. Rodgers.

* Present address: Enteric Disease Program, Naval Medical Research Institute Annex, 12300 Washington Avenue, Rockville, MD 20852, USA.
Mechanisms of pathogenesis in C. jejuni infections remain controversial. The organism has been reported to be invasive [3] and various toxins have been implicated in disease $[4,5]$. One such toxin is an enterotoxin with serological and ganglioside-recognition properties similar to those of cholera toxin $[6,7]$. C. jejuni has also been found to produce another distinctive toxin, the cytolethal distending toxin (CDT), which induces slow and progressive cytological changes in Chinese hamster ovary $(\mathrm{CHO})$ cells and other cells including Vero, HEp-2 and HeLa $[8,9]$. Three genes, designated $c d t A, c d t B$ and $c d t C$ and encoding proteins of 30,28 and $19 \mathrm{kDa}$, respectively, are necessary for the production of active CDT [9], but the role of this toxin in pathogenesis has yet to be established.

The production of other cytotoxins has also been described $[6,10-13]$ and some have been partially characterised [11,14]. Little is known about the structure and function of these cytotoxins but, in 
general, they are reported to be heat-labile, sensitive to trypsin degradation and $>14 \mathrm{kDa}$ as determined by size exclusion chromatography [12]. Cytotoxic activity has also been found associated with the lipopolysaccharide (LPS)-rich fraction of the organism [14], but currently the role of LPS in toxicity is unknown. It is probable that a combination of virulence factors act in concert to realise the full pathogenic potential of $C$. jejuni.

Porins are an intergral part of the cell membrane which permit cell-cell interaction as well as the exchange of material between the bacterial cell and the external environment $[15,16]$. They usually exist as $\beta$-barrels with $\beta$-strands that traverse the membrane and form channels of $c .1 \mathrm{~nm}$ diameter [17] and an exclusion limit of $5000 \mathrm{Da}$ [15]. Porins have been shown to activate splenocytes [18] and interleukin-1 (IL-1) and IL-6 gene expression in human monocytes [19]. Salmonella typhi porins stimulated a protective immune response in rabbits, by the induction of lymphokines leading to the activation of $\mathrm{T}$ cells [20]

The major outer-membrane protein (MOMP) of $C$. jejuni is a porin of $43 \mathrm{kDa}$ and is present in $c .60 \%$ of pathogenic strains [21-23]. When the MOMP was purified and reconstituted in a lipid bilayer, it formed a channel with a conductance of $8.82 \mathrm{nS}$ in $1 \mathrm{M} \mathrm{KCl}$ [23]. Conformational analysis of the assembled porin showed that it was a trimer formed by three folded monomers with a high degree of $\beta$-sheet secondary structure [22]. It was also found to be immunologically similar to the OmpC protein in Escherichia coli [21] and has been classified as part of the trimeric porin family [23].

This study describes the identification and characterisation of a cytotoxic porin-LPS complex produced by C. jejuni. Although there have been several previous reports (reviewed by Sears and Kaper [4] and Wassenaar [5]) describing the production of cytotoxins by $C$. jejuni, the present report is the first to identify a complex composed of a porin protein and LPS. These findings may lead to a more comprehensive understanding of toxin-mediated enteritis in campylobacter infections.

\section{Materials and methods}

\section{Bacterial strains and culture media}

C. jejuni strain 2483 , previously shown to produce a cytotoxin, was isolated from a patient with gastroenteritis $[10,11]$ and was characterised as Lior serotype 82 , biotype 1 and Penner serotype O11. The strain was passed twice on tryptic soy agar (TSA) containing sheep blood $5 \%$ and was stored at $-70^{\circ} \mathrm{C}$ in tryptic soy broth containing sheep blood $5 \%$. Thawed samples were cultured on TSA with sheep blood $5 \%$ before inoculation into Brucella broth (BBL), pre-equilibrated in an atmosphere of $\mathrm{O}_{2} 5 \%, \mathrm{CO}_{2} \quad 10 \%$ and $\mathrm{N}_{2} \quad 85 \%$. For batch preparation, a suspension of the organism was made equivalent in density to a McFarland number 8 standard and inoculated into $4 \mathrm{~L}$ of Brucella broth at a concentration of $2 \mathrm{ml} / \mathrm{L}$. Inoculated broths were incubated in stationary conditions in the gas mixture for $48 \mathrm{~h}$ at $37^{\circ} \mathrm{C}$, at which time they were in the stationary phase of growth.

\section{Isolation of cytotoxic complex}

Bacteria were harvested by centrifugation at $12000 \mathrm{~g}$ for $20 \mathrm{~min}$ at $4^{\circ} \mathrm{C}$ and the supernate was concentrated c. 40 -fold by ultrafiltration at $4^{\circ} \mathrm{C}$ in a stirred cell apparatus with a YM30 membrane $(30000$ mol. wt cutoff) (Amicon, Beverly, MA, USA). Protein was precipitated by the addition of ammonium sulphate to $80 \%$ saturation at $4^{\circ} \mathrm{C}$, collected by centrifugation at $12000 \mathrm{~g}$ for $30 \mathrm{~min}$ and resuspended in $50 \mathrm{mM}$ Tris$\mathrm{HCl}$ buffer, $\mathrm{pH}$ 7.0. The cytotoxic protein was purified with a Hewlett Packard 1050 series high-performance liquid chromatograph (HPLC) equipped with a diodearray detector. The protein concentrate was added at $1 \%$ of the total bed volume to a HiLoad $^{\mathrm{TM}} 16 / 60$ Superdex ${ }^{\mathrm{TM}} 75$ sizing column (Pharmacia Biotech, Uppsala, Sweden) and eluted with phosphate-buffered saline (PBS), $\mathrm{pH} 7.0$, at a flow rate of $1 \mathrm{ml} / \mathrm{min}$. Fractions were collected on a Gilson fraction collector and $50 \mu \mathrm{l}$ of each was evaluated for cytotoxic activity. The molecular mass of the native cytotoxic complex was determined by calibrating the column with low mol.wt standards (Pharmacia Biotech) dissolved in PBS. Cytotoxin-containing fractions were pooled concentrated with Centraprep-30 units (Amicon) and applied to a $7.5 \times 75 \mathrm{~mm}$ TSK DEAE-5PW column (Pharmacia Biotech). Proteins were eluted with a linear gradient of $0.2-0.25 \mathrm{M} \mathrm{NaCl}$ in $50 \mathrm{mM}$ Tris- $\mathrm{HCl}, \mathrm{pH}$ 7.0 , at a flow rate of $1 \mathrm{ml} / \mathrm{min}$. Fractions were collected, desalted by spin dialysis in Centricon-30 units (Amicon) and $50 \mu \mathrm{l}$ of each sample was assessed for cytotoxic activity.

The bacterial pellet recovered by centrifugation was suspended in $50 \mathrm{mM}$ Tris- $\mathrm{HCl}$, placed on ice and sonicated with a Branson Sonifier 450 sonicator (Branson Ultrasonic Corporation, Danbury, CT, USA), centrifuged at $12000 \mathrm{~g}$ for $10 \mathrm{~min}$ and the cell-sonicate supernate was processed in the same manner as the culture supernate.

\section{Polymerase chain reaction}

Genomic DNA was isolated from C. jejuni strain 2483 by a standard procedure [24]. Polymerase chain reaction (PCR) was conducted as outlined previously [25] with $50 \mathrm{ng}$ of genomic DNA and primers for $E$. coli verocytotoxins VT1a and VT1b, and VT2a and VT2 b at annealing temperatures of $42^{\circ} \mathrm{C}, 45^{\circ} \mathrm{C}$ and $50^{\circ} \mathrm{C}$. PCR was also performed with primers DZ3 and R009 specific for Helicobacter pylori cagA and 
primers F6 and R20 specific for $H$. pylori vacA gene as outlined previously [26]. The $H$. pylori Penner reference serotypes $\mathrm{O} 5$ and $\mathrm{O} 6$ were used in $\mathrm{PCR}$ reactions as positive controls for $\operatorname{cag} A$ and $v a c A$, respectively. The PCR methodology was as described for $\operatorname{cagA}$ [26] except that $100 \mathrm{ng}$ of chromosomal DNA/reaction was used for amplification of the vacA gene with 35 cycles of $95^{\circ} \mathrm{C}$ for $1 \mathrm{~min}, 58^{\circ} \mathrm{C}$ for $1 \mathrm{~min}$ and $72^{\circ} \mathrm{C}$ for $2 \mathrm{~min}$ with a final extension of $10 \mathrm{~min}$. PCR products were electrophoresed on an agarose $1 \%$ gel in Tris-acetate, EDTA-containing buffer ( $\mathrm{pH} 8.3$ ), stained with ethidium bromide and visualised on a transilluminator (Ultra-violet Products, San Gabriel, CA, USA).

\section{Cytotoxic activity and protein determination}

The amount of protein at each stage of the isolation procedure was quantified with the BCA protein assay (Pierce, Rockford, IL, USA). HEp-2, HeLa and CHO cells were grown in T-75 cell culture flasks (Costar, Cambridge, MA, USA) in Eagle's Minimal Essential Media (MEM) supplemented with fetal bovine serum (FBS; Sigma) $10 \%$. Cells were subcultured into 96-well plates $24 \mathrm{~h}$ before determination of cytotoxic activity. Cytotoxic activity for the three cell lines was quantified as described previously [8] and activities were expressed after incubation for $24 \mathrm{~h}$ as tissue culture dose 50 (TCD50). A TCD50 was defined as the amount of toxin, in $\mu \mathrm{g}$ of protein, required to induce cell rounding, cytoplasmic blebbing or vacuolation of the cytoplasm in $50 \%$ of the cells. Cell cultures were fixed for $10 \mathrm{~min}$ in absolute methanol and stained for $30 \mathrm{~min}$ with Giemsa (Gibco BRL, Grand Island, NY, USA). The specific activities were determined on culture supernates of $C$. jejuni and on preparations after each step of the purification procedure and expressed as number of TCD50/ $\mu \mathrm{g}$ of protein. Culture supernates of E. coli O157:H7 strains LCDC 3787 (H19), positive for verocytotoxin VT1 and LCDC 90-2380, positive for VT2, were used as controls for TCD50 determination in HEp-2 and HeLa cells. Vibrio cholerae O1, strain 755 , a cholera toxin-producing isolate, was used as a control in the $\mathrm{CHO}$ cell assay.

\section{Physical characterisation of the cytotoxic complex}

One $\mu \mathrm{g}$ of protein of the isolated cytotoxic material was mixed with an equal volume of $2 \times$ sample buffer containing $\beta$-mercaptoethanol and sodium dodecyl sulphate. The sample was boiled for $5 \mathrm{~min}$ and separated by SDS-PAGE on a homogeneous $12 \%$ gel, along with kaleidoscope pre-stained low mol.wt standards, and silver stained with a commercial kit (BioRad, Hercules, CA, USA). One- $\mu$ g samples of the isolated cytotoxic material were either heated at $70^{\circ} \mathrm{C}$ for $30 \mathrm{~min}$ or treated with trypsin in PBS at concentrations ranging from 0.03 to $1.25 \% \mathrm{w} / \mathrm{v}$ for $2 \mathrm{~h}$ at $37^{\circ} \mathrm{C}$. Residual trypsin activity was inactivated by addition of FBS to give a final concentration of
$20 \% \mathrm{v} / \mathrm{v}$ and incubated for $1 \mathrm{~h}$ at $37^{\circ} \mathrm{C}$. Heated and trypsin-treated samples were serially diluted two-fold in PBS before cell culture assay to determine the degree of activity remaining after the treatments. Heatinactivated trypsin and FBS alone were used as negative controls.

\section{$N$-Terminal sequencing of cytotoxin}

After electrophoresis of the cytotoxic material as above, the protein was transferred electrophoretically to a polyvinylidene diflouride (PVDF) membrane (BioRad) for $18 \mathrm{~h}$ at $100 \mathrm{~mA}$ in $10 \mathrm{mM} \mathrm{3-(cyclohexy-}$ lamino)-1-propane sulphonic acid (CAPS; Sigma) buffer, $\mathrm{pH} 11.0$, containing methanol $10 \% \mathrm{v} / \mathrm{v}$. The blot was stained with Coomassie Blue R-250 (BioRad) $0.1 \mathrm{w} / \mathrm{v}$ in methanol $50 \% \mathrm{v} / \mathrm{v}$ for $5 \mathrm{~min}$ and destained with methanol $50 \% \mathrm{v} / \mathrm{v}$ and acetic acid $10 \% \mathrm{v} / \mathrm{v}$. The immobilised protein band was excised and the protein was sequenced by Edman degradation on an Applied Biosystems model 473A protein sequencer (CHUL Research Center, Saint-Foy, Quebec, Canada) and analysed with Lasergene software from DNAStar, (Madison, WI, USA).

\section{Neutralisation and Western blot analysis}

Neutralisation studies were performed on the cytotoxic complex from $C$. jejuni with homologous polyclonal antiserum and with antisera against $E$. coli VT1, $E$. coli VT2, CDT from $C$. jejuni [8] and CDT from $E$. coli [8], cholera toxin from $V$. cholerae (Sigma) and cytotoxin B from Clostridium difficile (Techlab, Blacksburg, VA, USA). Normal rabbit serum was used as a negative control. Homologous antiserum was raised by intramuscular inoculation of New Zealand White rabbits with $0.5 \mathrm{ml}$ of a preparation of isolated cytotoxic material at $5 \mu \mathrm{g} / \mathrm{ml}$ emulsified in $0.5 \mathrm{ml}$ of Freund's incomplete adjuvant (FIA). This was followed, at weekly intervals for 4 weeks, by subcutaneous injection of the same antigen preparation in FIA. A 1 in 10 dilution of each antiserum was added to serial two-fold dilutions of the isolated cytotoxic material, starting at $1 \mu \mathrm{g} / \mathrm{ml}$ of protein. After incubation for $1 \mathrm{~h}$ at $37^{\circ} \mathrm{C}$, aliquots of each were added to HEp-2 cells and incubated for $24 \mathrm{~h}$ at $37^{\circ} \mathrm{C}$. Each antiserum was also assayed by Western blot analysis. $C$. jejuni cytotoxic complex, E. coli VT1 and VT2, C. jejuni CDT, E. coli CDT, $C$. difficile cytotoxin B and cholera toxin were each separated by SDS-PAGE and transferred to PVDF. These were washed with skimmed milk $5 \%$ for $1 \mathrm{~h}$ to prevent non-specific binding of antibody. A 1 in 500 dilution of each of the antisera in skimmed milk $1 \%$ containing Tween- $200.05 \% \mathrm{v} / \mathrm{v}$ was added to membranes for $2 \mathrm{~h}$ at room temperature. Membranes were probed with alkaline phosphataseconjugated goat anti-rabbit antibody (Boehringer Mannheim) $200 \mathrm{mU} / \mathrm{ml}$ for $1 \mathrm{~h}$ at room temperature and developed with 5-bromo-4-chloro-3-indolyl-phosphate and nitroblue tetrazolium. Western blot analysis 
and cytotoxicity assays were also performed on crude concentrated culture supernates from $C$. jejuni and other bacterial strains.

\section{Carbohydrate characterisation}

A total of $2 \mu \mathrm{g}$ (protein content) of the isolated cytotoxic material was assayed for the presence of LPS by the Limulus amoebocyte lysate (LAL) test according to the manufacturer's instructions (Pyrotell, Associates of Cape Cod, MA, USA). The toxic material and $E$. coli were each diluted 10-fold with pyrogen-free water in duplicate and $100 \mu \mathrm{l}$ of each dilution were incubated wtih $100 \mu \mathrm{l}$ of Pyortell in a $37^{\circ} \mathrm{C}$ water bath for $1 \mathrm{~h}$. Tubes were inverted and those containing a solid clot were considered positive. To determine whether LPS contributed to the cytotoxic activity of the material, 1$\mu \mathrm{g}$ (protein content) amounts of the sample were incubated for $1 \mathrm{~h}$ at $37^{\circ} \mathrm{C}$ with $5 \mathrm{U}$ of neuraminidase (Sigma) at pH 5.0, $3 \mathrm{U}$ of N-glycosidase $\mathrm{F}$ (Boehringer Mannheim) at $\mathrm{pH} 7.2$, or $10 \mathrm{mM}$ sodium metaperiodate (Sigma) for $90 \mathrm{~min}$ at room temperature. The residual cytotoxic activity was then assayed with HEp-2 and HeLa cells.

The carbohydrate moiety was identified with a glycan differentiation kit (Boehringer Mannheim) containing five unique digoxigenin-labelled lectins (Table 1).
Approximately $1 \mu \mathrm{g}$ of the isolated cytotoxic protein and $5 \mu \mathrm{g}$ of each carbohydrate standard were spotted on PVDF membranes and allowed to dry overnight at $37^{\circ} \mathrm{C}$. Membranes were probed for the co-purifying LPS according to the manufacturer's instructions. Those lectins that gave positive results were further examined by Western blot analysis with $15 \mu \mathrm{g}$ of each carbohydrate standard and $8 \mu \mathrm{g}$ of the test carbohydrate from the purified preparation. The isolated cytotoxic material from three separate batches was assayed for carbohydrate with a phenol-sulphuric acid assay [27]. SDS-PAGE and native PAGE were done wtih $10 \mu \mathrm{g}$ of the carbohydrate and gels were double stained, first with periodic acid-Schiff (PAS) [28] then with Coomassie Blue.

\section{Results \\ Identification and molecular characterisation of cytotoxic complex}

Cytological signs of intoxication caused by the cytotoxic complex included the formation of vacuoles in the cytoplasm of HEp-2 cells as compared with normal unaffected cells (Fig. la and b). Similar results were found with HeLa cells. The number of vacuoles in each cell ranged from one to five with $\geqslant 50 \%$ of the cytoplasm of some cells being affected. After $24 \mathrm{~h}$, the

Table 1. Specificities and the reactions of the lectins used in the carbohydrate determination

\begin{tabular}{|c|c|c|}
\hline Lectins & Specificity (linkage) & Reactivity \\
\hline Galanthus nivalis agglutinin (GNA) & $\operatorname{Man} \alpha(1-3), \alpha(1-6)$ or $\alpha(1-2)$-Man (terminally linked mannose) & +++ \\
\hline Maackia amurensis agglutinin (MAA) & Neu5Ac $\alpha(2-3)$-Gal (sialic acid terminally linked $\alpha(2-3)$ to galactose) & + \\
\hline Datura stramonium agglutinin (DSA) & $\mathrm{Gal} \beta(1-4) \mathrm{GlcNac}$ (galactose- $\beta(1-4)-\mathrm{N}$-acetylglucosamine) & + \\
\hline Arachis hypogaea (peanut) agglutinin (PNA) & $\mathrm{Gal} \beta(1-3) \mathrm{GalNac}$ (galactose- $\beta(1-3)-\mathrm{N}$-acetylgalactosamine) & - \\
\hline Sambucus nigra agglutinin (SNA) & $\begin{array}{l}\text { Neu5Ac } \alpha(2-6) \text {-Gal or GalNac (sialic acid terminally linked } \alpha(2-6) \text { to } \\
\text { galactose or N-acetylgalactosamine) }\end{array}$ & - \\
\hline
\end{tabular}

+++ , strong positive result; + , weak positive result; - , negative result

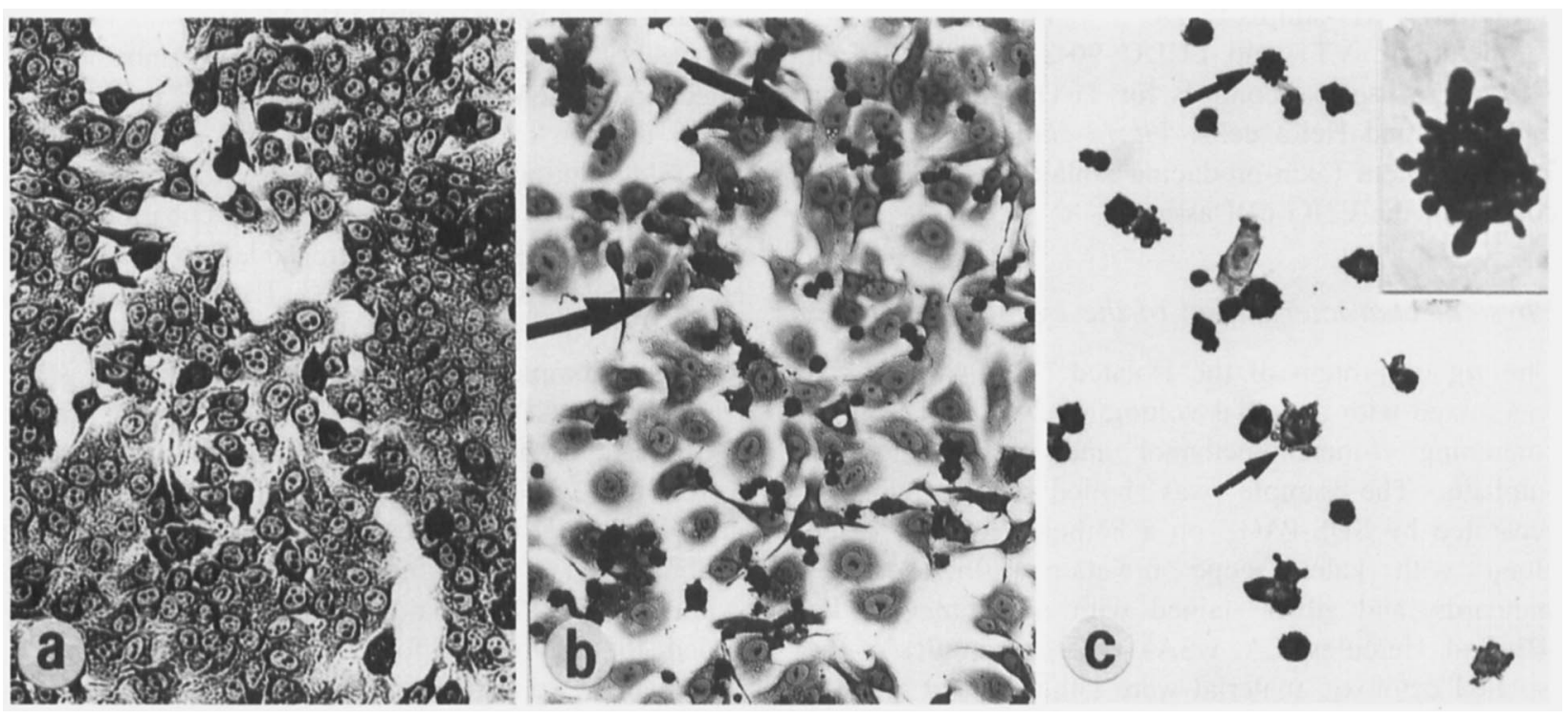

Fig. 1. Morphological changes induced in HEp-2 cells after treatment for $48 \mathrm{~h}$ with isolated $C$. jejuni cytotoxic porinLPS complex: A, control cells; B, cells intoxicated with $1 \mu \mathrm{g}$ (protein content) of cytotoxic complex, note the cytoplasmic vacuoles (arrowed). C, cells intoxicated with $10 \mu \mathrm{g}$ (protein content) of cytotoxic complex, note the cytoplasmic blebbing (arrowed and inset). (magnification $\times 140$ ). 
vacuoles diminished in size and the cells developed a rounded, highly refractile appearance. By $48 \mathrm{~h}$, cytoplasmic blebbing and nuclear condensation became more evident along with cell loss from the monolayer (Fig. 1c and inset). Toxicity was dose-dependent: at $1 \mu \mathrm{g}$ of protein/well, the vacuoles persisted up to $48 \mathrm{~h}$ while rounding occurred up to $72 \mathrm{~h}$; at $10 \mu \mathrm{g}$ of protein/well, vacuoles formed and dissipated within the first $12 \mathrm{~h},>50 \%$ of the cells were rounded and refractile by $24 \mathrm{~h}$ and, by $48 \mathrm{~h}, 80-100 \%$ of the cells had become rounded (Fig. 1c). Similar cytological changes were observed in all the cell lines when the whole bacterial cell sonicate was assayed for toxicity. C. jejuni strain 2483 produced low levels of CDT in the crude concentrate; however, this was neutralised with polyclonal antisera raised against either $C$. jejuni or $E$. coli CDT (data not shown).

Concentrated proteins from the culture supernate of $C$. jejuni strain 2483 possessing high levels of cytotoxic activity were found to elute from the Superdex 75 gel filtration column in the void volume, with a calculated native mol. wt of $>100 \mathrm{kDa}$ (Fig. 2a). This peak (peak A) was collected and applied to the TSK DEAE-5PW column. Cytotoxic activities of the TSK DEAE-5PW fractions showed that the toxin eluted at $c$. 0.21$0.22 \mathrm{M} \mathrm{NaCl}$ (Fig. 2b, peak B). The two-column purification procedure produced a single protein band of $45 \mathrm{kDa}$ which was revealed by silver staining (Fig. 2c). The toxic activities at each stage of the purification procedure are shown in Table 2. The isolated cytotoxic complex demonstrated greatest toxic activity for HEp-2 cells and the lowest for CHO cells. The cytotoxin was inactivated by heat treatment at $70^{\circ} \mathrm{C}$ for $30 \mathrm{~min}$, but was resistant to trypsin at the concentrations tested.

\section{Polymerase chain reaction}

Oligonucleotide primers specific for $E$. coli VT1 and VT2 failed to produce amplicons corresponding to Aand B-subunits of mature verotoxin types 1 and 2 . Also, primers specific for the $\operatorname{cag} A$ and $v a c A$ genes of $H$. pylori failed to generate amplicons with $C$. jejuni DNA. All primers gave positive reactions with their corresponding control DNA.

\section{Protein alignment}

The cytotoxic protein consisted of a single protein with a calculated mol.wt of $45 \mathrm{kDa}$. The excised band was subjected to N-terminal sequencing and a total of 31 amino acid residues was elucidated: TPLEEAIKDVDVSGVLRYRYDTGNFDKNFVN. This sequence contained several hydrophobic and charged residues and had a predicted iso-electric point of 4.35. A search through the Beckman Center for Molecular and Genetic Medicine (Stanford University) revealed that the protein had $97 \%$ homology with the MOMP (TPLEEAIKDVDVSGVLRYRYDTGNFDKNF* ${ }^{*}$ ) from

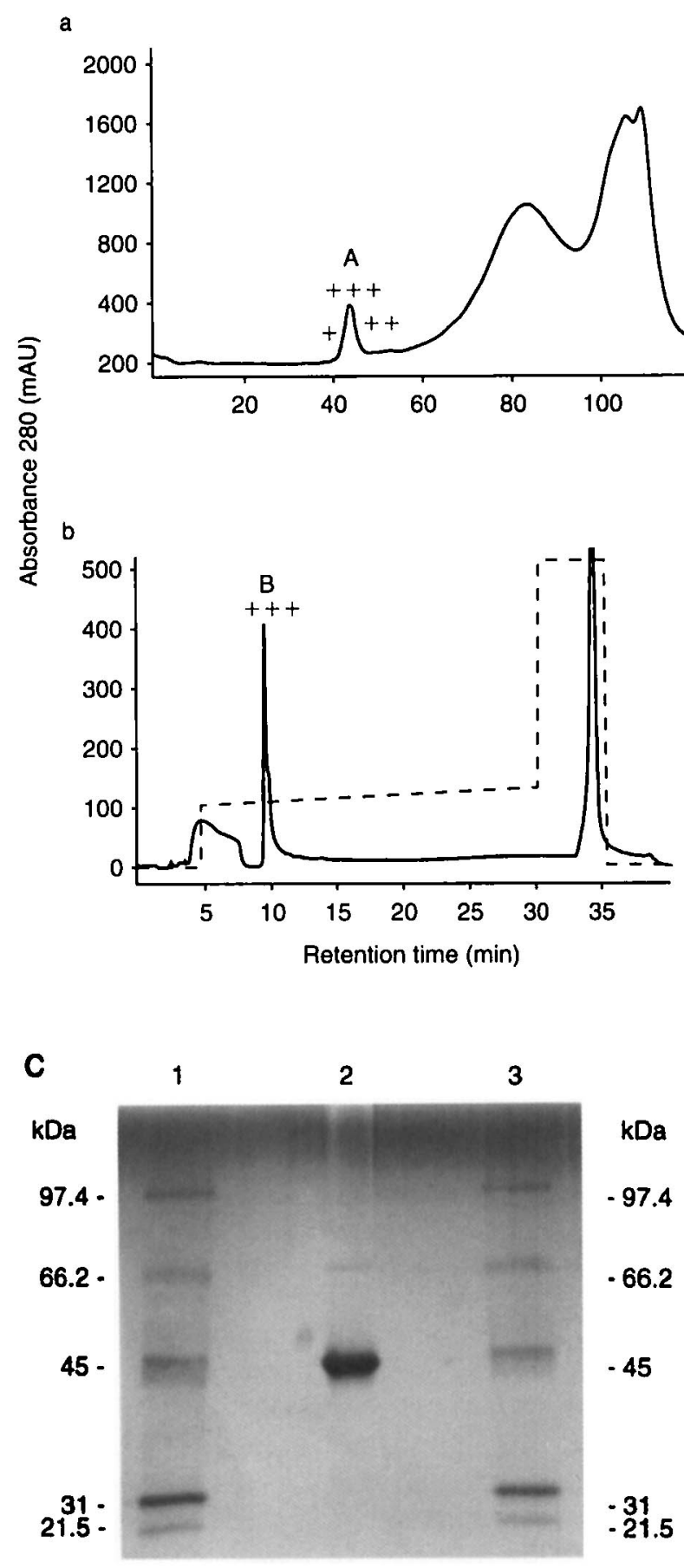

Fig. 2. Isolation of the cytotoxic porin-LPS complex from proteins concentrated from the culture supernate: a, fractionation on a Superdex 75 gel filtration column; b, fractionation of peak A on a TSK DEAE-5PW column;,$+++>70 \%$ of HEp- 2 cells rounded by $48 \mathrm{~h}$; ,$++ 50-70 \%$ cells rounded by $48 \mathrm{~h} ;+,<50 \%$ cells rounded by $48 \mathrm{~h}$; c, silver-stained SDS-PAGE. Lanes 1 and 3, mol. wt standards $(\mathrm{kDa}) ; 2,1 \mu \mathrm{g}$ (protein content) of C. jejuni isolated cytotoxic complex (peak B from the DEAE column).

C. jejuni [22]. This MOMP has been characterised as a porin. The cytotoxic porin detected in the present studies also shared $56 \%$ and $63 \%$ sequence homology with the $45-\mathrm{kDa}$ and $51-\mathrm{kDa}$ OMPs, respectively, from Wolinella recta [29]. 
Table 2. Cytotoxic activity of $C$. jejuni preparations at each step of purification

\begin{tabular}{lccc}
\hline & \multicolumn{3}{c}{$\begin{array}{c}\text { Cell culture specific activity } \\
\text { (No. of TCD50/ } \mu \text { g protein) }\end{array}$} \\
\cline { 2 - 4 } Organism and preparation & HEp-2 & HeLa & CHO \\
\hline C. jejuni strain 2483 & & & \\
$\quad$ Culture supernate & 1.56 & 0.51 & 0.51 \\
Superdex 75 16/60 & 1.61 & 3.88 & 0.97 \\
TSK DEAE-5PW & 20.1 & 7.49 & 1.87 \\
Toxin controls* & & & \\
E. coli strain LCDC 3787 (H19) (VT1) & 0.35 & 0.17 & ND \\
E. coli strain LCDC 90-2380 (VT2) & 1.48 & 2.89 & ND \\
V. cholerae O1, strain 755 (cholera toxin) & ND & ND & 0.48 \\
\hline
\end{tabular}

$\mathrm{ND}$, not determined.

${ }^{*}$ Assayed as concentrated culture supernates.

\section{Neutralisation and Western blot analysis}

Polyclonal antisera raised against $E$. coli VT1 and VT2, $C$. jejuni and $E$. coli CDT, cholera toxin and $C$. difficile cytotoxin $\mathrm{B}$ failed to neutralise the cytotoxic effects elicited by the $C$. jejuni toxic complex in cell culture. However, when this cytotoxic complex was serially diluted, incubated with rabbit polyclonal antiserum raised against the cytotoxic protein and added to HEp- 2 cells, the TCD50 occurred at a dilution of 1 in 2 of the toxin preparation, whereas the TCD50 in the presence of the normal rabbit serum was at a dilution of 1 in 32. Antiserum raised against the cytotoxic protein showed immunological reactivity in Western blots with the cytotoxic $45-\mathrm{kDa}$ protein in the purified preparation after TSK-DEAE fractionation. Antisera raised to the other toxins showed no crossreactivity with either the cytotoxin or carbohydrate by immunoblot analysis. Western blots of crude concentrated filtrates from various cytotoxic strains of Campylobacter spp. showed the presence of a protein with a mol.wt similar to that of the porin (Fig. 3), whereas no bands were detected in the blots from the uninoculated broth or in the filtrates from Aeromonas veronii and $E$. coli VT1 strains used as controls.

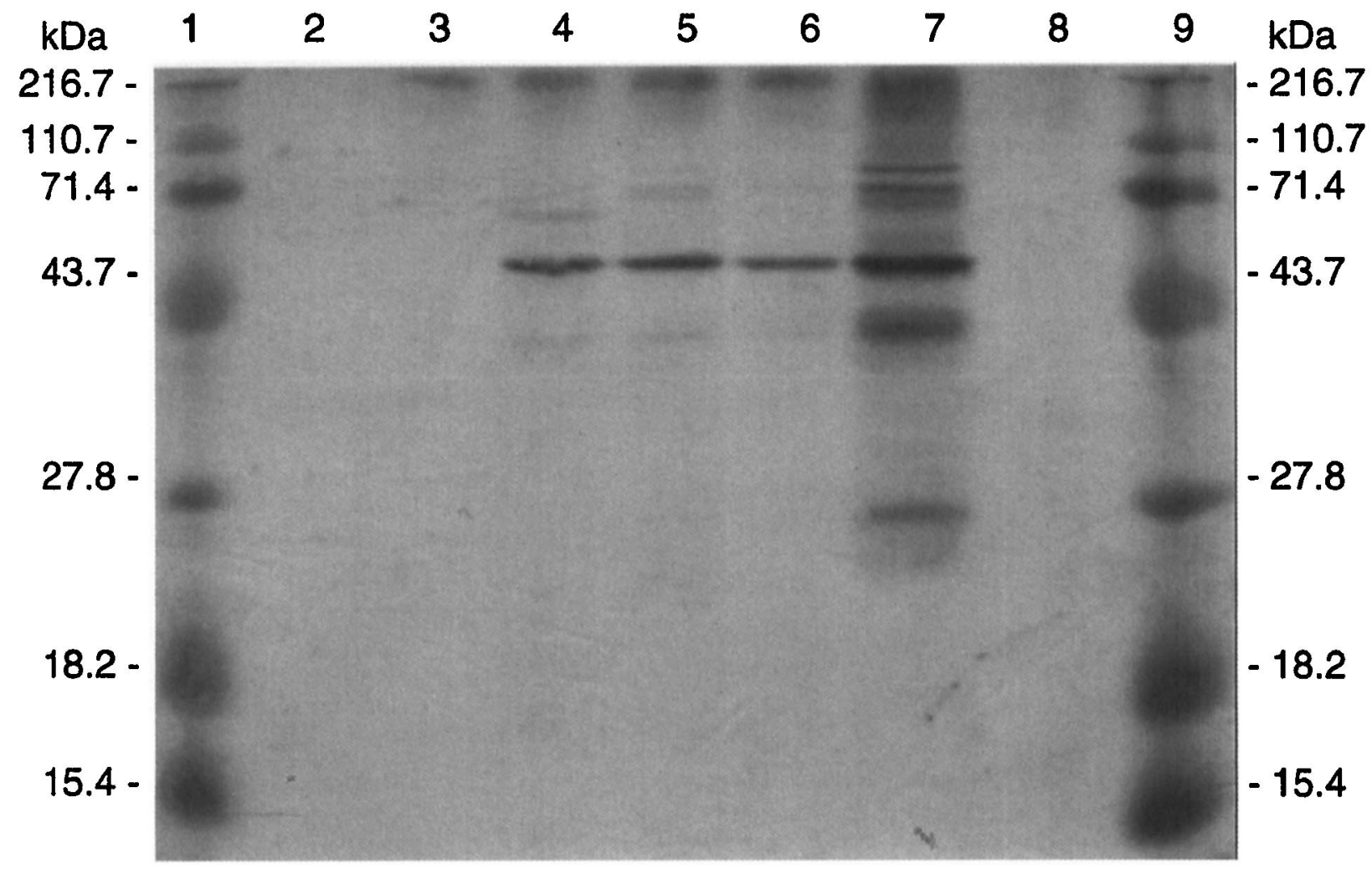

Fig. 3. Western blot analysis of the isolated cytotoxic porin-LPS complex from Campylobacter spp. with $40 \mu \mathrm{g}$ (protein content) of crude, concentrated filtrate and homologous rabbit antiserum. Lanes $\mathbf{1}$ and $\mathbf{9}$, pre-stained standards (kDa); 2, uninoculated broth; 3, Aeromonas veronii LCDC A2297; 4, C. coli strain 8682; 5, C. jejuni LCDC 16336; 6, C. jejuni LCDC 3969; 7, C. jejuni strain 2483; 8, E. coli LCDC 3787 (VT1 producer). 


\section{Lipopolysaccharide identification and carbohydrate analysis}

The isolated cytotoxic material and E. coli LPS were assayed for the presence of endotoxin by a Limulus amoebocyte lysate test. The cytotoxic material produced a strong positive result at a dilution of 1 in 128000 , signifying the presence of LPS. The E. coli LPS also gave a positive result. To determine whether or not the cytotoxic activity associated with the complex resided in the protein component, samples were incubated with $10 \mathrm{mM}$ sodium metaperiodate, to oxidise the free hydroxyl groups present on visceral hexoses, with $5 \mathrm{U}$ of neuraminidase, to cleave sialic acid residues, and with $3 \mathrm{U}$ of $\mathrm{N}$-glycosidase $\mathrm{F}$, to cleave asparagine bound $\mathrm{N}$-glycans. Dilution of the samples were then assayed for cytotoxic activity in HEp-2 and HeLa cells and expressed as TCD50 endpoints. The titres for purified toxin incubated with and without metaperiodate or the two enzymes were 32 in Hep-2 and 28 in HeLa cells. This indicated that the degradation of the carbohydrate component of the LPS had no effect on the toxicity elicited by the porin.

The carbohydrate component of the LPS was characterised with digoxigenin-labelled lectins (Table 1) and the data revealed a complex of different subunits. Lectin GNA reacted strongly with the purified material and suggested a high proportion of terminally linked mannose. The lectins MAA and DSA also gave positive but weaker results, indicating the presence of sialic acid terminally linked $\alpha(2-3)$ to galactose and galactose- $\beta(1-4)-\mathrm{N}$-acetylglucosamine as well as hybrid $\mathrm{N}$-glycan structures in the complex, respectively. The remaining lectins showed no reactivity for the carbohydrate complex. The proportion of carbohydrate to protein in the purified material was calculated to be $4: 1$. PAS staining revealed a high mol.wt carbohydrate which did not appear as a discrete band as did the protein component of the complex but, instead, occupied a broad range of sizes (Fig. 4). Double staining of purified cytotoxin in native PAGE gels showed no protein component, in contrast to samples boiled in denaturing buffer before SDS-PAGE (Fig. 4). Western blots with the lectins (Fig. 5) showed that the high mol.wt smear seen following PAS staining (Fig. 4) was carbohydrate in nature with high reactivity for GNA (Fig. 5).

\section{Discussion}

A cytotoxin from strains of $C$. jejuni that was heatlabile, trypsin-sensitive and induced characteristic rounding of HEp-2, HeLa and MRC-5 cells was first documented by Yeen et al. [30]. Guerrant et al. [12] also described a cytotoxic component which was heat labile at $60^{\circ} \mathrm{C}$, was partially sensitive to trypsin $0.25 \%$ and had a mol. wt $>14 \mathrm{kDa}$. The cytotoxic component identified by these workers could not be neutralised with antisera raised against $E$. coli verocytotoxins or $C$. difficile toxin B [12]. A subsequent report indicated the presence of a Shiga-like cytotoxin from $C$. jejuni which could be neutralised with monoclonal antibodies directed against the B subunit of the mature Shigatoxin; however, these workers also detected a cytotoxin which could not be neutralised by the same monoclonal antibody [31]. In addition, Guerrant and colleagues [12], unlike Yeen et al. [30], found cytotoxic activity in

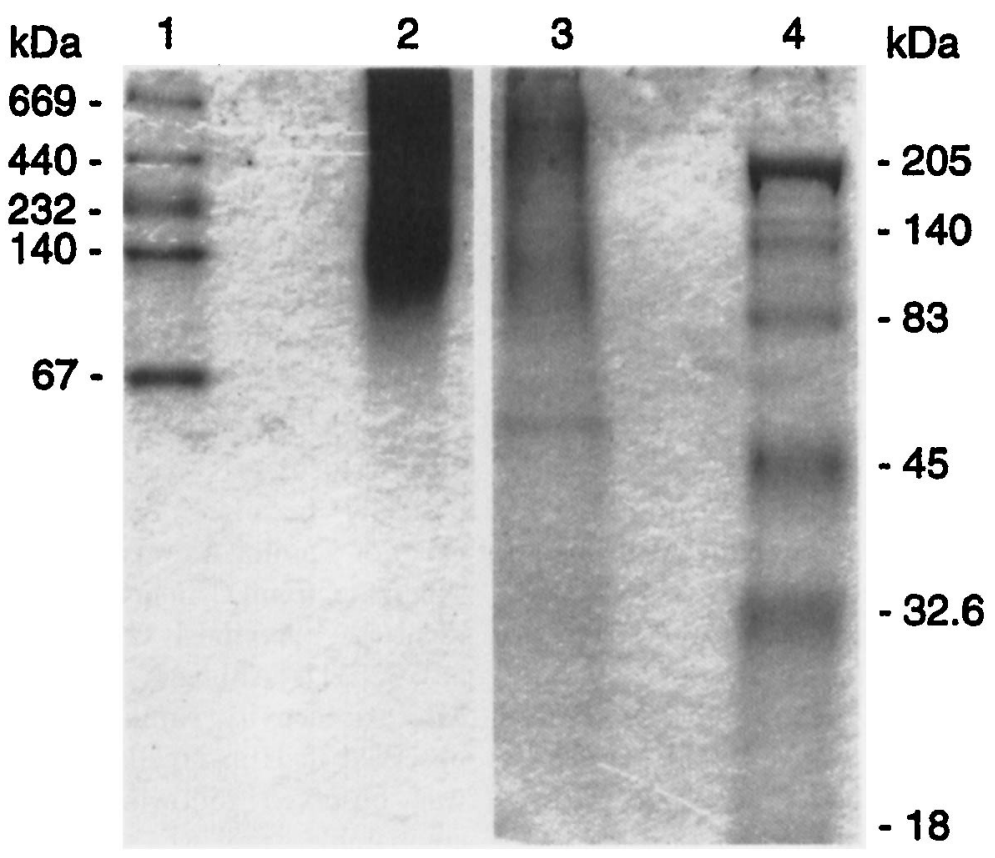

Fig. 4. Double staining of native-PAGE (lanes 1 and 2) and SDS-PAGE (lanes 3 and 4) gels with periodic acid-Schiff (PAS) and Coomassie Blue. Lane 1, native mol.wt standards (Pharmacia); 2, $10 \mu \mathrm{g}$ (carbohydrate content) of native cytotoxic complex; 3, $10 \mu \mathrm{g}$ (carbohydrate content) of cytototoxic complex denatured by heat and SDS; 4, kaleidoscope pre-stained mol. wt standards $(\mathrm{kDa})$. 


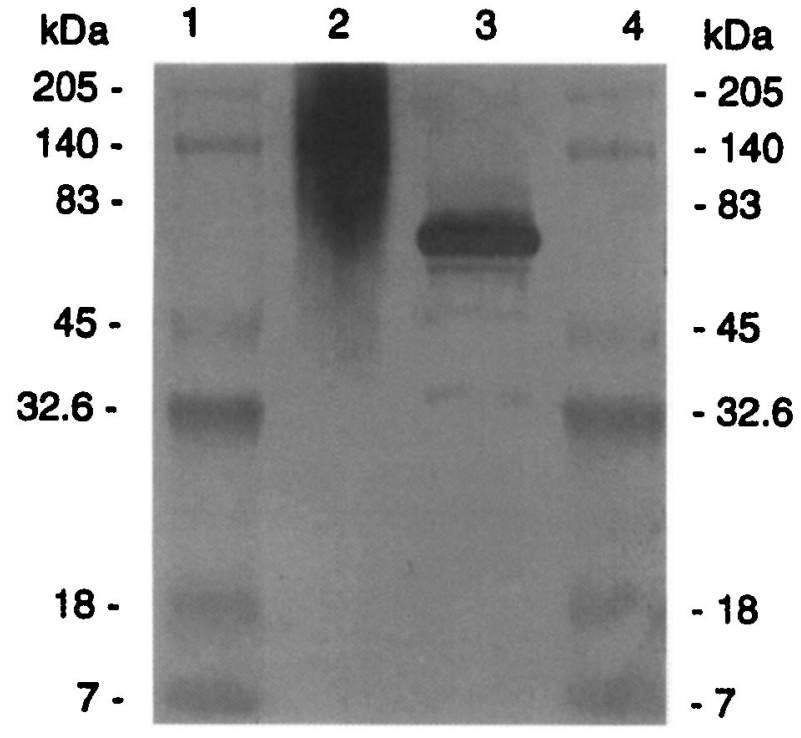

Fig. 5. Western blot analysis of the isolated cytotoxic complex with the digoxigenin-labelled lectin GNA. Lanes 1 and 4, kaleidoscope pre-stained standards $(\mathrm{kDa}) ; 2,10 \mu \mathrm{g}$ (carbohydrate content) of the cytotoxic complex; 3, $15 \mu \mathrm{g}$ carboxypeptidase $\mathrm{Y}$ served as a positive control by binding the lectin GNA through its terminal mannose.

sonicated whole bacterial cell preparations. In the present study cytotoxic activity was detected both in culture supernates and in supernates of sonicated $C$. jejuni strain 2483 cells (data not shown).

A cytotoxic complex comprising a porin and LPS was isolated and characterised. Previous studies showed a cytotoxic factor present in LPS-rich fractions from $C$. jejuni [14]; however, it was not known what role the LPS played in toxicity. Misawa et al. [32] found that the expression of their cytotoxin was elevated when the $C$. jejuni was grown in Brucella broth. However, contrary to their additional findings regarding the activity of their cytotoxin in various culture media [32], the present studies indicated that the cytotoxic effects elicited by the porin had a more profound cytopathic effect on HEp-2-cells than on $\mathrm{CHO}$ cells when the cells were maintained in media containing FBS. The increase in activities observed in the different cell lines may be caused by the relative amounts of the receptor required for binding of the porin-LPS complex. Previous reports have implicated LPS in the adhesion of $C$. jejuni to epithelial cells as well as to intestinal mucus and also showed that this process could be inhibited by periodate oxidation [3]. As the cytotoxic activity of the porin-LPS was maintained following treatment with periodate in both HEp-2 and HeLa cells, it would appear that adhesion of the toxic complex is facilitated by components other than LPS. It is possible that expression of the porin protein may be involved in binding the organism to host cells; however, Fauchere et al. [33] indicated that the MOMP was not involved in adherence to HeLa cells. From these studies it would appear that, although the LPS may mediate attachment of organisms to host cells [3], the porin component binds the cytotoxic complex.

Although the mode of action of the cytotoxic porin remains unclear, the morphological changes induced by it are similar in nature to those induced by other, well-characterised bacterial cytotoxins. During early stages of intoxication the cytotoxic porin induced vacuole formation in HEp-2 and HeLa cells similar to that produced by $H$. pylori vacuolating toxin [34]. However, no PCR products were generated with primers specific for $\operatorname{cag} A$ and $v a c A$ genes of $H$. pylori [26] suggesting that the genes encoding vacuole induction by the $C$. jejuni porin were distinct from those in $H$. pylori.

When intoxication of host cells with the $C$. jejuni cytotoxic porin was extended beyond $24 \mathrm{~h}$, vacuoles dissipated while the cytoplasmic blebbing and nuclear condensation typical of verocytotoxin and diphtheria toxin became more evident. Verocytotoxin and diphtheria toxin are both known to interfere with protein synthesis, leading to programmed cell death or apoptosis [35, 36]. PCR-based screening of $C$. jejuni with verocytotoxin-specific primers was negative and confirmed the low stringency hybridisation experiments of Moore et al. [31] and this suggested that the C. jejuni cytotoxic complex was distinct from verocytotoxin. It is possible that the porin from $C$. jejuni induces holes in the cell membrane in a manner similar to that resulting from Staphylococcus aureus $\alpha$-toxin [36]. Recently, the cytotoxic effects elicited by Salmonella Typhimurium porin suggested that porins directly affect the cytoskeleton and the membrane ultrastructure of HEp-2 cells [37]. In addition, porins from Neisseria spp. have also been shown to inhibit polymerisation of actin in human neutrophils [38] while porins from $S$. Typhimurium have been found to induce both an inflammatory response [39] and the release of cytokines from human monocytes and lymphocytes [40].

Isolation of the cytotoxic porin protein by chromatofocusing and determination of its iso-electric point by Coomassie Blue staining and Western blotting of isoelectric focus gels (data not shown) were unsuccessful, probably because of interference from LPS. The isolation protocol was also applied to a culture supernate from $C$. jejuni strain 3969 which had been reported previously to produce a cytotoxin $[13,32,41]$. Although the strain produced a lower cytotoxic activity, similar morphological changes were observed in HEp- 2 cells and a protein of similar size was observed following SDS-PAGE. A protein of comparable mol.wt was also present in crude concentrated culture supernates from other cytotoxic strains of Campylobacter spp., indicating that the release of the porin-LPS complex was not unique to C. jejuni strain 2483. Carbohydrates were also present 
in the cytotoxic product isolated from $C$. jejuni strain 3969. The difference in cytotoxic activity between strain 3969 (low toxin activity) and 2483 (high toxin activity) could be a growth-rate dependent phenomenon, as the release of the porin-LPS complex may occur most avidly during cell death or may be lost during active replication of the organism. Therefore, strains with a higher growth rate could produce quantitatively more cytotoxic complex [42]. A vacuolating cytotoxin similar to that produced by $H$. pylori was detected in the stools of children with diarrhoea in the absence of a disease agent [43]. Indeed, it is possible that many bacteria possess the ability to induce vacuole formation in host cells by the release of porin material from dead or dying organisms [42].

Lectin studies showed that the carbohydrate portion of the LPS which co-purified with the porin possessed terminally linked mannose as well as sialic acid terminally linked $\alpha(2-3)$ to galactose and to galactose- $\beta(1-4)-\mathrm{N}$-acetylglucosamine complexed with hybrid N-glycan structures. Based on the thermostable somatic (O) antigen, the strain of $C$. jejuni used in this study was type O11. The positive result with the lectin MAA suggests that the strain may be related to serotype O19 [44]. The LPS from the O19 serostrain of $C$. jejuni has core structures that mimic those present on GM1 and GDla gangliosides and other strains of $\mathrm{O} 19$ have been linked to post-infectious neuropathies [45]. The presence of terminally linked mannose in the LPS of the O11 serotype in this study may be significant. Treatment of the isolated complex with sodium metaperiodate, neuraminidase and $\mathrm{N}$ glycosidase $F$ had no effect on the toxicity elicited by the complex, suggesting that the LPS is not an integral component of the cytotoxic activity but that it may play a protective role. Indeed, it is possible that it may have interfered with the enzymic degradation by trypsin and may offer an explanation for the disparity in trypsin inactivation data of previous reports. Under native conditions, the LPS probably forms complexes with the porin and protects it from discrete staining with Commassie Blue. The cytotoxic protein is revealed by Coomassie Blue or silver staining only after boiling in sample buffer containing SDS and $\beta$ mercaptoethanol before SDS-PAGE. As the porin from $C$. jejuni has been classified as part of the trimeric porin family, it was not unexpected that it must be heat denatured in order to resolve the protein component of the cytotoxic complex [17].

When characterisation of the cytotoxic porin is complete and the encoding gene has been cloned and sequenced, a fuller understanding of the role of the porin in clinical campylobacteriosis will be forthcoming. Such evaluations may suggest potential roles for the porin-LPS complex as a diagnostic tool for the detection of either the organism or its cytotoxin or, additionally, as a recombinant vaccine for prevention and control of campylobacter disease.
We thank Dr Arthur O. Tzianabos, Channing Laboratories, Harvard Medical School, and Dr Malcolm Perry, National Research Council of Canada for helpful suggestions regarding the carbohydrate nature of the complex and Dr John Penner, University of Toronto, for serotyping the $C$. jejuni strains used in this study. This work was supported by a US Public Health grant, AI35787 awarded to F.G.R. by the National Institutes of Health and by Health Canada.

\section{References}

1. Skirrow M, Blaser M. Clinical and epidemiologic considerations. In: Nachamikin I, Blaser M, Tompkins L (eds) Campylobacter jejuni: current status and future trends. Washington DC: ASM. 1992: 3-8.

2. Tauxe R. Epidemiology of Campylobacter jejuni infections in the United States and other industrialized nations. In: Nachamkin I, Blaser M, Tompkins L (eds) Campylobacter jejuni: current status and future trends Washington DC: ASM. 1992: 9-19.

3. McSweegan E, Walker RI. Identification and characterization of two Campylobacter jejuni adhesions for cellular and mucous substrates. Infect Immun 1986; 53: 141-148.

4. Sears CL, Kaper JB. Enteric bacterial toxins: mechanisms of action and linkage to intestinal secretion. Microbiol Rev 1996; 60: $167-215$.

5. Wassenaar TM. Toxin production by Campylobacter spp. Clin Microbiol Rev 1997; 10: 466-476.

6. Kawaguchi M, Takama K, Suzuki S. Distribution and solubilization of Campylobacter jejuni toxins. Microbios Letters 1989; 42: 113-118.

7. Suzuki S, Kawaguchi M, Mizuno K, Takama K, Yuki N. Immunological properties and ganglioside recognitions by Campylobacter jejuni-enterotoxin and cholera toxin. FEMS Immunol Med Microbiol 1994; 8: 207-211.

8. Johnson WM, Lior H. A new heat-labile cytolethal distending toxin (CLDT) produced by Campylobacter spp. Microb Pathog 1988; 4: 115-126.

9. Pickett CL, Pesci EC, Cottle DL, Russell G, Erdem AN, Zeytin H. Prevalence of cytolethal distending toxin production in Campylobacter jejuni and relatedness of Campylobacter sp. $c d t B$ genes. Infect Immun 1996; 64: 2070-2078.

10. Mahajan S, Rodgers FG. Virulence of Campylobacter jejuni for chicken embryos. J Clin Microbiol 1989; 27: 1377-1379.

11. Mahajan S, Rodgers FG. Isolation, characterization, and hostcell-binding properties of a cytotoxin from Campylobacter jejuni. J Clin Microbiol 1990; 28: 1314-1320.

12. Guerrant RL, Wanke CA, Pennie RA, Barrett LJ, Lima AAM, O'Brien AD. Production of a unique cytotoxin by Campylobacter jejuni. Infect Immun 1987; 55: 2526-2530.

13. Johnson WM, Lior H. Cytotoxic and cytotonic factors produced by Campylobacter jejuni, Campylobacter coli, and Campylobacter laridis. J Clin Microbiol 1986; 24: 275-281.

14. Mizuno K, Takama K, Suzuki S. Characteristics of cytotoxin produced by Campylobacter jejuni strains. Microbios 1994; 78: 215-228.

15. Welte W, Nestel U, Wacker T, Diederichs K. Structure and function of the porin channel. Kidney Int 1995; 48: 930-940.

16. Mowa NR, Nakamura $K$, Inouye $M$. Gene structure of the ompA protein, a major surface protein of Escherichia coli required for cell-cell interaction. $J \mathrm{Mol}$ Biol 1980; 143: $317-328$.

17. Nikaido H. Porins and specific channels of bacterial outer membranes. Mol Microbiol 1992; 6: 435-442.

18. Sommese L, Donnarumma G, Cipollaro de L'ero G, Marcatili A, Vitiello M, Galdiero M. Growth hormone modulates IL- $\alpha$ and INF- $\gamma$ release by murine splenocytes activated by LPS or porins of Salmonella typhimurium. J Med Microbiol 1996; 45: $40-47$.

19. Galdiero F, Cipollaro de L'ero G, Donnarumma G, Marcatili A, Galdiero F. Interleukin-1 and interleukin-6 gene expression in human monocytes stimulated with Salmonella typhimurium porins. Immunology 1995; 86: 612-619.

20. Gonzalez CR, Isibasi A, Ortiz-Navarrete V et al. Lymphocytic proliferative response to outer-membrane proteins isolated from Salmonella. Microbiol Immunol 1993; 37: 793-799.

21. Kervella M, Fauchère J-L, Fourel D, Pagès J-M. Immunological cross-reativity between outer membrane pore proteins of 
Campylobacter jejuni and Escherichia coli. FEMS Microbiol Lett 1992; 99: 281-286.

22. Bolla J-M, Loret E, Zalewski M, Pagès J-M. Conformational analysis of the Campylobacter jejuni porin. J Bacteriol 1995; 177: 4266-4271.

23. Huyer M, Parr T, Hancock R, Page W. Outer membrane protein of Campylobacter jejuni. FEMS Microbiol Lett. 1986; 37: 247-250.

24. Sambrook J, Fritsch EF, Maniatis T. Molecular cloning: A laboratory manual, 2nd edn. Cold Spring Harbor, NY, Cold Spring Harbor Laboratory Press, 1992.

25. Pollard DR, Johson WM, Lior H, Tyler S, Rozee KR. Rapid and specific detection of verotoxin genes in Escherichia coli by the polymerase chain reaction. J Clin Microbiol 1990; 28: $540-545$

26. Xiang Z, Censini S, Bayeli $\mathrm{P}$ et al. Analysis of expression of CagA and VacA virulence factors in 43 strains of Helicobacter pylori reveals that clinical isolates can be divided into two major types and that CagA is not necessary for expression of the vacuolating cytotoxin. Infect Immun 1995; 63: 94-98.

27. Dubois M, Gilles KA, Hamilton JK, Rebers PA, Smith F. Colormetric method for detection of sugars and related substances. Anal Chem 1956; 28: 350-356.

28. Segrest J, Jackson R. Molecular weight determination of glycoproteins by polyacrylamide gel electrophoresis in sodium dodecyl sulfate. In: Ginsburg V (ed) Methods of enzymology New York, Academic Press. 1972: 54-63.

29. Kennell WL, Holt SC. Extraction, purification, and characterization of major outer membrane proteins from Wolinella recta ATCC 33238. Infect Immun 1991; 59: 3740-3749.

30. Yeen WP, Puthucheary SD, Pang T. Demonstration of a cytotoxin from Campylobacter jejuni. J Clin Pathol 1983; 36: 1237-1240.

31. Moore MA, Blaser MJ, Perez-Perez GI, O'Brien AD. Production of a Shiga-like cytotoxin by Campylobacter. Microb Pathog 1988; 4: 455-462.

32. Misawa N, Ohnishi T, Itoh K, Takahashi E. Development of a tissue culture assay system for Campylobacter jejuni cytotoxin and the influence of culture conditions on cytotoxin production. $J$ Med Microbiol 1994; 41: 224-230.

33. Fauchere J, Kervella M, Rosenau A, Pagès J-M, Fendi C. In vitro study of virulence factors of enteric Campylobacter spp. In: Nachamkin I, Blaser M, Tompkins L (eds) Campylobacter jejuni: current status and future trends. Washington DC, ASM 1992: $168-175$.

34. Weel FL, van der Hulst RWM, Gerrits Y et al. The interrelationship between cytotoxin-associated gene A, vacuolating cytotoxin, and Helicobacter pylori-related diseases. $J$ Infect Dis 1996; 173: 1171-1175.

35. Inward C, Williams J, Chant I et al. Verocytotoxin-1 induces apoptosis in Vero cells. $J$ Infect 1995; 30: 213-218.

36. Chen Y, Zychlinsky A. Apoptosis induced by bacteria pathogens. Microb Pathog 1994; 17: 203-212.

37. De Martino L, Nazzaro C, Concilio S, Galdiero $M$. Morphological changes induced in HEp-2 cells by Salmonella typhimurium porins. J Submicrosc Cytol Pathol 1995; 27 : 445-449.

38. Bjerknes R, Guttormsen H-K, Solberg CO, Wetzler LM Neisserial porins inhibit human neutrophil actin polymerization, degranulation, opsonin receptor expression, and phagocytosis but prime the neutrophils to increase their oxidative burst. Infect Immun 1995; 63: 160-167.

39. Galdiero F, Tufano MA, Galdiero M, Masiello S, Di Rosa M Inflammatory effects of Salmonella typhimurium porins. Infect Immun 1990; 58: 3183-3186.

40. Galdiero F, Cipollaro de L'ero G, Benedetto N, Galdiero M, Tufano MA. Release of cytotokines induced by Salmonella typhimurium porins. Infect Immun 1993; 61: 155-161.

41. Misawa N, Ohnishi T, Itoh K, Takahashi E. Cytotoxin detection in Campylobacter jejuni strains of human and animal origin with three tissue culture assay systems. $J$ Med Microbiol 1995; 43: 354-359.

42. Menzl K, Maier E, Chakraborty T, Benz R. HlyA hemolysin of Vibrio cholerae $\mathrm{O} 1$ biotype $\mathrm{El}$ Tor identification of the hemolytic complex and evidence for the formation of anionselective ion-permeable channels. Eur J Biochem 1996; 240: 646-654.

43. Luzzi I, Covacci A, Censini S et al. Detection of a vacuolating cytotoxin in stools from children with diarrhea. Clin Infect Dis 1996; 23: $101-106$.

44. Penner JL, Aspinall GO. Diversity of lipopolysaccharide structures in Campylobacter jejuni. J Infect Dis 1997; 176 Suppl 2: S135-S138.

45. Allos BM. Association between Campylobacter infection and Guillain-Barré syndrome. J Infect Dis 1997; 176 Suppl 2: S125-S128. 